\title{
Effects of withania somnifera root extracts on serotonin secretion in suiz albino mice
}

\author{
Benson Muriuki Githaiga ${ }^{1, *}$, Elijah Lelmen ${ }^{2}$, Elizabeth Muthoni Mwangi ${ }^{3}$, Paul Njenga Waithaka ${ }^{4}$ \\ ${ }^{1}$ Student'Department of Biochemistry and Molecular Biology, ${ }^{1,2,3}$ Egerton University, Njoro. School of Biological Sciences, ${ }^{4}$ University of \\ Nairobi, Nairobi, Kenya
}

*Corresponding Author: Benson Muriuki Githaiga

Email:bgmuriuki@gmail.com

\begin{abstract}
Pain is a common manifestation of presence of disease or physical injury in humans. High levels of serotonin in the plasma has been associated with pain. This study aimed at determining the effect of Withania somnifera root extracts on serotonin levels in Suiz albino mice. W. somnifera root samples were collected and ground to small pieces. Ethanol, n-butanol, xylene and methanol were used to extract metabolites from the ground root materials using hot extraction technique. The mice were injected with the extracts separately and serotonin levels determined over a period of $12 \mathrm{~h}$ at $2 \mathrm{~h}$ intervals. Serotonin concentration was determined using Beer Lamberts method. Light absorbance by the extracts varied significantly $\left(\mathrm{F}=50.2011 \mathrm{P}=1.25 \times 10^{-07}\right.$. The concentrations of serotonin from mice injected with the metabolites from the selected solvents varied significantly $(\mathrm{F}=23.3269 \mathrm{P}=0.0000469$. In addition, there was no significant difference in light absorbance values obtained by Panadol, methanol and ethanol extracts. $(\mathrm{F}=3.7178 \mathrm{P}=0.089$ ). Extracts from $\mathrm{W}$. somnifera have the ability to reduce serotonin levels in plasma. Further studies on the mechanisms involved in reducing serotonin levels by W. somnifera in blood need to be carried out. There is need for mass production of metabolites from W. somnifera.
\end{abstract}

Keywords: Withania somnifera, Root extracts, Serotonin, Suiz albino mice.

\section{Introduction}

Serotonin (5-hydroxytryptamine) is a monoamine neurotransmitter. It is a derivative of tryptophan (Kauray et al., 2013). Serotonin is predominantly found in the gastrointestinal tract, platelets and in the central nervous system of animals. Approximately $90 \%$ of the total serotonin is located in the enterochromaffin cells in the alimentary canal, where it is used to regulate intestinal movements (Maheswari and Manisha, 2015). The serotonin secreted from the enterochromaffin cells eventually finds its way out of tissues into the blood where it is stored (Rai et al., 2016).

High levels of plasma serotonin have been observed to be in direct proportionality with increase in pain (Abeer et al., 2016). However, since W. somnifera extracts have been found to reduce pain, the effect of the plant on the serotonin levels in blood has not yet been established. Reduction of plasma serotonin levels will be taken as an indicator to reduction in pain up to the required standards (Sivamani et al., 2014). Substances that reduce pain will be expected to reduce serotonin levels to the required amounts for positive physiological processes or at least reduction of serotonin levels as a course for pain reduction (Khan et al., 2015).

Withania somnifera (Solanaceae) is a xerophytic plant, found in the drier parts of Kenya, India, Sri Lanka, Afghanistan, Baluchistan and Sind and is distributed in the Mediterranean regions where it grows wildly on waste places and on road sides (Umadevi et al., 2016). It is also cultivated for medicinal purposes in fields and open grounds throughout India but not much research has been done in Kenya. The chemistry of W. somnifera has been extensively studied and over thirty-five chemical constituents have been identified, extracted, and isolated (Giri, 2013). The biologically active chemical constituents are alkaloids (isopelletierine, anaferine), steroidal lactones (withanolides, withaferins), saponinscontaining an additional acyl group (sitoindoside VII and VIII), and withanolides with a glucose at carbon 27 (sitoindoside IX and X) (Wadhwa et al., 2015). W. somnifera is also rich in iron. Research conducted at the Department of Pharmacology, University of Texas Health Science Center indicated that extracts of Ashwagandha produce GABA-like activity, which may account for the herb's anti-anxiety effects (Durg et al., 2016). The chemopreventive effect was demonstrated in a study of ashwagandha root extract on induced skin cancer in Swiss albino mice given ashwagandha before and during exposure to the skin cancer-causing agent (7,12-dimethylbenz (a) anthracene) (Kedia and Chattarji, 2018).

W. somnifera - Dunal (locally known as Ashwagandha) is widely used in Ayurvedic medicine, the traditional medical system of India. It is an ingredient in many formulations prescribed for a variety of conditions such as arthritis and rheumatism (Jayanthi et al., 2014). The plant has also been utilized as a general tonic to increase energy, improve overall health and longevity, and prevent disease in athletes, the elderly, and during pregnancy (Nabeel et al., 2013). It has been reported that W. somnifera exerts significant effect on the endocrine system. Based on the observations, that $\mathrm{W}$. somnifera provides protection from free radical damage in the mouse liver; studies were conducted to determine the efficacy of W. somnifera in regulating thyroid function (Vidvashankar et al., 2014). The treatment significantly increased the serum levels of 3, 3'5tri-iodothyronine (T3) and tetra-iodothyronine (T4), while the hepatic concentrations of glucose 6-phosphatase activity and hepatic iodothyronine 5'-monode-iodinase activity did not change significantly (Alam et al., 2015).

Back pain and arthritis are increasingly becoming a complex clinical challenge in the present society. According to the World Health Organization (WHO), up to $60 \%$ of the 
human population suffers from these complications at some stage in their life time (Bharathi et al., 2015). Arthritis is characterized by the wearing of joints' soft bone, caused by failure of osteopoline, a protein responsible for calcium deposition in the osteoclasts of the bone and cartilage. This condition predisposes an individual to other clinical disorders thus impacting negatively on their general health status (Khan et al., 2015). To address pain caused by musculo-skeletal disorders and providing a permanent solution has been a great challenge over generations. The present clinical remedies to these pains give a short lived relieve and therefore treatment with a longer lasting relieve from pain or total pain reduction is lacking. W. somifera, being a potent pain modulator would probably modulate serotonin levels in the blood stream thereby reducing joint and back pains. This study aimed at determining serotonin levels in Swizz albino mice injected with root extracts of W. somnifera using xylene, methanol, ethanol, normal butanol and water as solvents.

\section{Materials and methods Study area}

The study was conducted at Egerton University, main campus Njoro in Kenya. Egerton University is located in Njoro sub county with coordinates as $0^{\circ} 23^{\prime}$ south, $35^{\circ} 35^{\prime}$ and an altitude of $200 \mathrm{~m}$ above sea level. Temperature range between $17-22^{\circ} \mathrm{C}$ While the average annual rainfall is $100 \mathrm{~mm}$ (Amata et al., 2014).

\section{Sample collection and preparation}

W. somnifera root samples were collected from Baringo County, around Chemeron Campus, Egerton University around noon when physiological processes of the plants were expected to be optimal. Approximately 10 healthy plants were uprooted by digging the surrounding earth to reach the tip of the taproots. A pair of secateurs was used to chop the plant borders and separate roots from stems. The root samples were packed in sterile plastic bags and transported to the Department of Biological Sciences laboratories Egerton University, Njoro. The samples were dried in the shade for 1 month. Extraction of crude extracts using selected organic solvents was carried out serially (Amitabha et al., 2016).

\section{Preparation of the solvents}

The following solvents were prepared and used as guided by Abeer et al. (2016).

1. $1.171 \mathrm{~g}$ of ethanol extracts which was dissolved to make 20 milliliters with distilled water $(0.05855 \mathrm{~g} / \mathrm{ml})$.

2. $1.027 \mathrm{~g}$ of $\mathrm{n}$-butanol extracts that was dissolved to make 20 milliliters solution with distilled water $(0.05135 \mathrm{~g} / \mathrm{ml})$.

3. $1.256 \mathrm{~g}$ of xylene extracts which was dissolved to make 20 milliliters with distilled water $(0.0628 \mathrm{~g} / \mathrm{ml})$.

4. $1.082 \mathrm{~g}$ of methanol extracts that was dissolved to make 20 milliliters solution with distilled water $(0.0541 \mathrm{~g} / \mathrm{ml})$.

\section{Extraction of crude extracts}

Extraction of crude extracts was carried out using hot extraction technique (Sivamani et al., 2014). Five hundred grams dry plant roots were ground to powder form and placed in a Winchester bottle containing 1.5 liters of distilled methanol. Incubation at room temperature $\left(23 \pm 2^{\circ} \mathrm{C}\right.$ for $24 \mathrm{~h}$ was carried out followed by filtration using Whitman number 1 filter papers. Distilled methanol was repeatedly added to the residue until it became colorless each washing being allowed $24 \mathrm{~h}$ before filtration. The filtrate was transferred into a round bottomed flask which fitted into the rotary evaporator. A second round bottomed flask was fitted on the opposite side to the first so as to collect the solvent being cooled (Tanna et al., 2014).

A fraction of methanol crude extract was transferred into a separating funnel up to about three-quarters full then to five-sixths full with methanol and thoroughly shaken. The water based extracts were drained into a beaker while ethanol based ones were put into a new Winchester bottle. The polar extracts were washed with n-butanol in the separating funnel until final washing $n$-butanol was colorless as above, adding every fraction to the Winchester bottle. This resulted in n-butanol-phase polar extract and methanol phase polar extract. This was repeated with xylene and ethanol.

\section{Withania somnifera extract bioassay with mice Selection and preparation of mice}

Five sets of four healthy males and mature albino mice (Fig.1) were obtained from The Department of Biological Sciences, Egerton University. The selected mice were kept in quiet and spacious cages to acclimatize while being fed ad libitum with standard mice pencils (which are in form of pellets) and water (The Prevention of Cruelty to Animals Act chapter 59 of 1960). The first set of 4 mice was then injected with $2 \mathrm{ml}$ of $\mathrm{W}$. somnifera root extract methanol fraction. This was repeated using ethanol, n-butanol, water, and xylene extracts. Blood was harvested according to Khan et al. (2015). Blood serotonin levels was determined over a period of $12 \mathrm{~h}$ at $2 \mathrm{~h}$ intervals, recorded and compared for the five sets. The sixth set was injected with $2 \mathrm{ml}$ of $\mathrm{W}$. somnifera extract that had been boiled for 10 minutes from the best performing extract fraction. Serotonin levels were taken at intervals of 2 hours for 5 times after every 2 hours and recorded. Blood serotonin levels were determined at 2 hourly intervals for 12 hours and recorded. The negative control set was had blood serotonin levels determined without any treatment with the extracts. For the positive control experiment, Panadol was used as an non-steroidal anti-inflamatory drug (Kauray et al., 2013). 


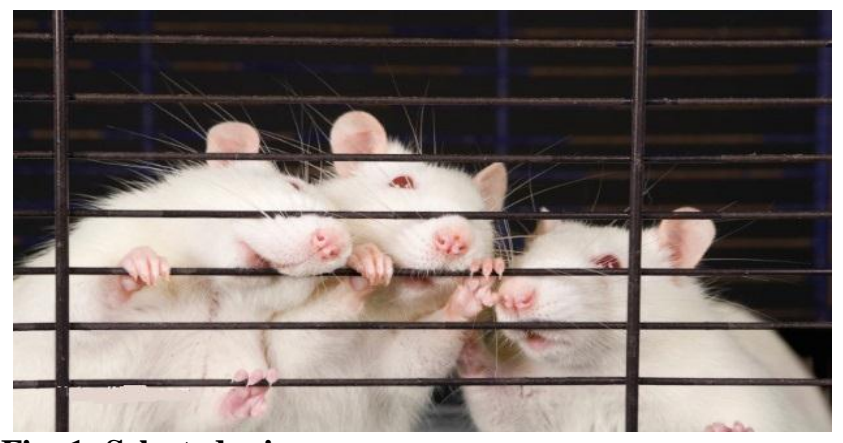

Fig. 1: Selected mice

\section{Determination of serotonin levels}

Platelet-rich plasma was prepared from 1 to $1.5 \mathrm{~mL}$ of blood from each mouse (Kamal et al., 2017). The platelets were spun down at $1600 \mathrm{~g}$ for 20 minutes at 0 to $4^{\circ} \mathrm{C}$. The supernatant was discarded and the platelets stored in a deepfreezer. Distilled water up to $1 \mathrm{ml}$. was added to the button of platelets, and thoroughly suspended. Then $0.2 \mathrm{ml}$ of a $10 \%$ solution of $\mathrm{ZnSO}_{4} .7 \mathrm{H}_{2} \mathrm{O}$ was added, followed, after briefly shaking, by $0.1 \mathrm{ml}$ of $1 \mathrm{M} \mathrm{NaOH}$. After vigorous shaking for one minute, the test-tubes were centrifuged at $1600 \mathrm{~g}$ for 15 minutes and then $0.5 \mathrm{ml}$ of the water-clear supernatant was put in a test-tube, $0.15 \mathrm{ml}$ of concentrated HCI added, and serotonin fluorescence checked at 295 and $540 \mathrm{~nm}$ using a spectrophotometer. A blank $(1 \mathrm{ml}$ of distilled water $)$ and one or more standards $(1 \mathrm{ml}$ of a $0.5 \mu \mathrm{g} / \mathrm{ml}$ solution of $5 \mathrm{HT}$ base) was run throughout the procedure.

\section{Determination of serotonin concentration}

The mean concentrations of serotonin from mice treated with Withania somnifera was determined using Beer Lamberts equation (Alam et al., 2015);

$$
\mathrm{A}=\sum \mathrm{mcl}
$$

where; $\mathrm{A}=$ Absorbance, $\sum \mathrm{m}=$ Molar extinction coefficient (6718), $\mathrm{C}=$ Concentration and $\mathrm{l}=$ path length of $1 \mathrm{~cm}$.

\section{Data analysis}

The experiment was laid down in a completely randomized design (CRD). The spectrophotometric readings were taken for the blood samples and tabulated. The data on serotonin levels were analyzed using GENSTAT Software (Version 15) and the treatment means compared using LSD. These data were also entered in spread sheets for subsequent generation of graphs and analysis of variance (ANOVA) tables to establish relationships and correlations between serotonin concentrations and $\mathrm{W}$. somnifera root fractions.

\section{Results}

Light absorbance by distilled water, ethanol, methanol, n-butanol and xylene extracts

The absorbance values in distilled water ranged from 1.459 to 1.196 (Table 1). However, in Ethanol, the range was 2.301-2.685. In methanol, absorbance varied from $2.017-2.405$. In addition, the range of absorbance in $\mathrm{n}$ butanol was 1.356- 1.865. Besides, in xylene, absorbance varied from 0.518-0.740. Light absorbance by distilled water, ethanol, methanol, n-butanol and xylene varied significantly $\left(\mathrm{F}=50.2011 \mathrm{P}=1.25 \times 10^{-07}\right)$.

Table 1: Values of absorbance at $295 \mathrm{~nm}$ obtained when different sets of Suiz albino mice were treated with root extracts of W. somnifera using different extracting solvents

\begin{tabular}{|c|c|c|c|c|}
\hline $\begin{array}{c}\text { Distilled } \\
\text { water }\end{array}$ & Ethanol & Methanol & n-butanol & Xylene \\
\hline 1.459 & 2.685 & 2.094 & 1.356 & 0.740 \\
\hline 1.985 & 2.433 & 2.405 & 1.865 & 0.518 \\
\hline 1.930 & 2.445 & 1.995 & 1.789 & 0.719 \\
\hline 1.196 & 2.301 & 2.017 & 1.475 & 0.629 \\
\hline
\end{tabular}

\section{Relationship between absorbance and concentration of the metabolites}

The y-intercept of the best line of fit was at 0.2 (Fig. 2). Absorbance values at 0.6, 1.7, 1.8, 2.2 and 2.4 were the same with concentration values of $0.07,0.23,0,24,0.33$ and 0.37 respectively.

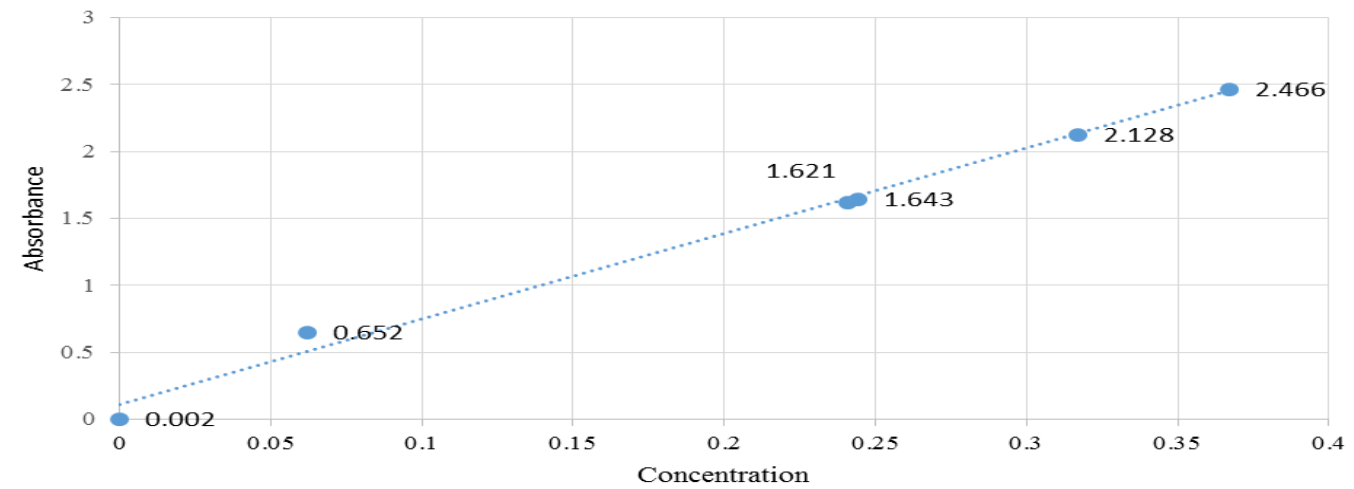

Fig. 2: Relationship between absorbance and concentration of serotonin from mice treated with different cold extracts of $\mathrm{W}$. somnifera roots 


\section{Concentrations of the metabolites extracted using the selected solvents}

The concentration of metabolites extracted from W. somnifera using ethanol varied from $0.342 \times 10^{-3}$ to $0.399 \times 10^{-3}$; methanol $\left(0.297 \times 10^{-3}-0.358 \times 10^{-3}\right)$; n-butanol $\left(0.202 \times 10^{-3}-0.277 \times 10^{-3}\right)$ and xylene $\left(0.077 \times 10^{-3}-0.110 \times 10^{-3}\right)$ (Table 2). The concentrations of the serotonin from mice injected with metabolites from the selected solvents varied significantly $(\mathrm{F}=23.3269 \mathrm{P}=0.0000469)$.

Table 2: Concentrations of serotonin from mice treated with W. somnifera different solvents root extracts multiplied by a factor of $10^{-3}$.

\begin{tabular}{|c|c|c|c|}
\hline Ethanol & Methanol & $\begin{array}{c}\text { n- } \\
\text { butanol }\end{array}$ & Xylene \\
\hline 0.399 & 0.300 & 0.202 & 0.110 \\
\hline 0.362 & 0.311 & 0.277 & 0.077 \\
\hline 0.364 & 0.358 & 0.266 & 0.107 \\
\hline 0.342 & 0.297 & 0.219 & 0.093 \\
\hline
\end{tabular}

\section{Comparison between absorbance values of W. somnifera root extracts with Panadol}

The light absorbance values of extracts with Panadol varied from 0.288 to 0.830 . However, in methanol the range was 0.660-2.351. Besides, in ethanol extracts, the absorbance values varied from $0.738-1.986$. There was no significant difference in light absorbance values obtained in Panadol, methanol and ethanol extracts $(\mathrm{F}=3.717845 \mathrm{P}=$ 0.089 )

Table 3: Comparison between W. somnifera root extracts absorbance values and a positive control Panadol on serotonin secretion.

\begin{tabular}{|c|c|c|}
\hline Panadol & Methanol & Ethanol \\
\hline 0.830 & 2.351 & 1.986 \\
\hline 0.587 & 0.660 & 0.738 \\
\hline 0.288 & 1.299 & 0.777 \\
\hline 0.429 & 1.962 & 0.972 \\
\hline
\end{tabular}

\section{Conclusion}

Extracts from W. somnifera have the ability to reduce serotonin levels in plasma. There is need to determine the mechanisms in which the extracts use in reducing serotonin concentration in blood. Mass production of W. somnifera extracts need to be carried out.

\section{Discussion}

W. somnifera ethanol root extracts had the highest absorbance values followed closely by methanol root extracts, n-butanol and finally xylene root extracts at a wavelength of $295 \mathrm{~nm}$ (Table 1). These results differed with a previous study carried out in India (Krutika et al., 2016). The solvents so used could have targeted different metabolites other than those that evoke serotonin secretion and its subsequent recruitment to the platelets (Dey et al., 2014). In addition, Rai et al. (2016) maintained that solvents could have had effect on positive down regulation of serotonin receptors thus low serotonin absorbance and concentrations as was shown by n-butanol and xylene extracts. The low absorbance values shown by xylene could be explained by the interaction the solvents has with the pigments present in the metabolites (Jayanthi et al., 2014).

The relationship between absorbance and concentration of the metabolites are presented in Fig. 2. The higher the concentration, the higher was the absorbance values. This agreed with study carried out by Ramakanth et al. (2018) on relieving pain in humans using extracts from $\mathrm{W}$. somnifera. Similarity in the extracted metabolites may have contributed to the observed results (Nabeel et al., 2013).

Serotonin concentration from ethanol extracts was the highest compared to other solvents (Table 2). This indicated that it was able to recruit serotonin to the site of tissue trauma more effectively than the other root extracts (Giri, 2013). This was also confirmed by the high absorbance values obtained in the current study. However, these results differed with a previous study where methanol had the highest concentration (Alam et al., 2015). This may be explained by differences in the accumulated metabolites in the plants used in the two studies (Ramin et al., 2018).

After heat-treatment of the two best performing extracts, it was observed that methanol extracts produced higher serotonin concentrations than ethanol. This agreed with previous studies carried out elsewhere (Kauray et al., 2013; Mohamed et al., 2014). This could be explained by differences in polarity that solvents obtain when they gain some heat (Kedia and Chattarjia, 2018). In addition, secondary metabolites extracted using n-butanol and xylene showed very low levels of serotonin absorbance and thus concentration compared to methanol and ethanol extracts. This differed with a previous study where the two solvents gave higher concentrations than methanol. This may attributed to the geographical differences in which the plants from which the metabolites were extracted were obtained (Kamal et al., 2017). Dar et al. (2015), asserted that the environment in which $\mathrm{W}$. somnifera grow dictates the type and composition of the secondary metabolites it accumulates (Tanna et al., 2014).

Serotonin obtained using ethanol and methanol extracts produced higher absorbance values than those obtained using Panadol (Table 3). This disagreed with a previous study by Umadevi et al. (2016). This may be attributed to variations in the extracted metabolites (Bharathi et al., 2015). Although Panadol was expected to inhibit serotonin secretion more than the former, the values obtained proved otherwise probably due to individual animal internal factors (Wadhwa et al., 2015). In addition, this could also be due to the number of serotonin receptors on individual animal down regulated by Panadol as it does not fully inhibit serotonin secretion (Alam et al., 2015).

\section{References}

1. Abeer, A. A., Mahitab, E., Mohamed, E., Ehab, R., Aboelfetoh, M. A., Abdel, R. H. and Farrage, H. (2016). Effects of the Aqueous Seed Extract of Withania somnifera (Ashwagandha) against Pilocarpine-induced Convulsions in Rats. Int J Pharm Sci Rev Res. 41(1):116-121. 
2. Alam, W., Dar, N. J. and Hamid, P. (2015). Methanolic extracts of Withania somnifera leaves, fruits and roots possess antioxidant properties and antibacterial activities. BMC Complementary and Alternative Medicine; 12(175):7-8.

3. Amata, R, L., Otipa, M. J., Waiganjo, M., Wabule, M., Thuranira, E. G., Erbaugh, M and miller, S. (2014). Incidence, prevalence and severity of passion fruitfungal disease in major production regions of Kenya. J Appl Biosci; 20:1146-1152.

4. Amitabha, D., Shyam, S. C. and Vikas, K. (2016). Low dose effects of a Withania somnifera extract on altered marble burying behavior in stressed mice. J Int Ethnopharmacol; 10 (2):1-4

5. Bharathi, P., Seshayamma, V., Jagannadharao, G. H. and Sivakumar, N. (2015). Evaluation of Antidepressant Activity of Aqueous Extract of Withania Somnifera [Aswagandha] Roots in Albino Mice. IOSR J Pharm Biol Sci; 10(1):27-29.

6. Dar, N. J., Hamid, A. and Ahmad, M. (2015). Pharmacologic overview of Withania somnifera, the Indian Ginseng. Cell and Molecular Life Sciences; 72:4445-60.

7. Davis, L. and Kuttan, G. (2014). Effect of Withania somnifera on CTL activity, J Exp Clin Cancer Res; 21(1):115-118.

8. Dey, A., Chatterjee, S. S. and Kumar, V. (2014). Comparison of the adaptogenic efficacy of three different Withania somnifera extracts in mice. Indian J Pharmacol; 10: 46-58.

9. Durg, S., Dhadde, S. B., Vandal, R., Shivakumar, B. S. and Charan, C. S. (2016). Withania somnifera (Ashwagandha) in neurobehavioural disorders induced experimental animals (Albino rats). J Med Plants Stud; 4(1):78-83.

10. Giri, K.R. (2013). Comparative study of anti-inflammatory activity of Withania somnifera (Ashwagandha) with hydrocortisone in identification of an active component and its mechanism of action. PLoS One; 8:e77189.

11. Jayanthi, M. K., Prathima, C., Huralikuppi, J. C., Suresha, R. $\mathrm{N}$ and Muralidhar, J. (2014). Anti-depressant effects of Withania somnifera fat (Ashwagandha ghrutha) extract in experimental mice. Int J Pharm Biol Sci; 3(1):33-42.

12. Kamal, S., Majid, A. and Saeid, H. (2017). Medicinal plants effective on serotonin Level: A Systematic review. J Pharm Res Int; 19(4): 1-12.

13. Kaurav, B. P., Wanjari, M. M., Chandekar, A., Chauhan, N. S. and Upmanyu, N. (2013). Influence of Withania somnifera on obsessive compulsive disorder in mice. Asian Pac J Trop Med; 5:380-384.

14. Kedia, S. and Chattarji, S. (2018). Marble burying as a test of the delayed anxiogenic effects of acute immobilisation stress in mice. J Neurosci; 5:45-60.

15. Khan, M. A., Subramaneyaan, M., Arora, V. K., Banerjee, B. D. and Ahmed, R. S. (2015). Effect of Withania somnifera (Ashwagandha) root extract on amelioration of oxidative stress and autoantibodies production in collagen-induced arthritic rats, J Complement Integr Med, 12(2):117-125.

16. Krutika, J., Swagata, T., Kalpesh, P., Praveen, K. and Nishteswar, K. (2016). Studies of Ashwagandha (Withania somnifera Dunal). Int J Pharm Biol Arch; 7(1): 1- 11.
17. Maheswari, R. and Manisha, P. (2015). Withania Somnifera L root extract ameliorates toxin induced cytotoxicity. Int $J$ Pharma Sci Res; 6(5): 5:848-855.

18. Mohamed, M., El-Sayed, Z. and El-Boshy. P. (2014). Effect of Withania somnifera extracts on some selective biochemical, hematological, and immunological parameters in Guinea pigs experimental infected with E. Coli. ISRN. Methods; 233:150157.

19. Nabeel, A., Sabreen, A. and Hadi, R. (2013). Antimicrobial activities of Withania Somnifera crude extract. Scientia Agriculturae; 4(3):74-76.

20. Rai, M., Jogee, P. S., Agarkar, G., dos Santos, C. A. (2016). Anticancer activities of Withania somnifera: Current research, formulations, and future perspectives. Pharm Biolo; 54:189-97.

21. Ramakanth, G.S.H., Uday, C. K., Kishan, P.V., Usharani, P. (2016). A randomized, double blind placebo controlled study of efficacy and tolerability of Withaina somnifera extracts in knee joint pain. J Ayurvenda Integractive med. 7:151-157.

22. Ramin, N. D., Afshar, Z., Hossein, N., Seyed, M., Homayoun, S., Fatemeh, N., Arezoo, M., and Yadollah, A. (2018). Effects of Withania somnifera on Reproductive System: A Systematic Review of the Available Evidence. BioMed Res Int; 4:1-18.

23. Sivamani, S. Krutika, J. and Swagata, J. (2014). Antiinflammatory activity of Withania somnifera leaf extract in stainless steel implant induced inflammation in adult zebrafish. J Genet Eng Biotechnol; 14:27-40.

24. Tanna, I. R., Aghera, B. H., Ashok, B. K. and Chandola, H. M. (2014). Protective role of Ashwagandharishta and flax seed oil against maximal electroshock induced seizures in albino rats. $J$ Altern Med; 33(1):114-118.

25. Umadevi, M., Rajeswari, R., Rahale, C. S., Selvavenkadesh, S., Pushpa, R. and Kumar, K. S. (2016). Traditional and medicinal uses of Withania somnifera. J Microbiol; 7: 234251.

26. Vidyashankar, S., Thiyagarajan, O. S., Varma, S. R., Kumar, L. M. S., Babu, U. V. and Patki, P. S. (2014). Withania somnifera supercritical $\mathrm{CO}_{2}$ extract derived with anolides mitigates Bisphenol A induced mitochondrial toxicity in HepG2 cells. Toxicology Reports; 1:1004-1012.

27. Wadhwa, R., Singh, R., Gao, R., Shah, N., Widodo, N. and Nakamoto, T. (2015). Water extract of ashwagandha leaves has anticancer activity. Pharm Innov; 1:102-10.

How to cite this article: Githaiga B. M, Lelmen E,
Mwangi E. M, Waithaka P. M, Effects of withania
somnifera root extracts on serotonin secretion in suiz albino
mice, J Pharm Biolog Sci. October-December,
2018;6(4):109-113

